\title{
The Capacity of Primary Care for Improving Evidence- Based Care: Early Findings From AHRQ's EvidenceNOW
}

\author{
Sarab J. Shoemaker, PbD, PbarmD ${ }^{1}$ \\ Robert J. McNellis, MPH, $P A^{2}$ \\ Darren A. DeWalt, MD, MPH \\ 'Health Policy Practice, Abt Associates, Inc, Cambridge, Massachusetts \\ ${ }^{2}$ Center for Evidence and Practice Improvement, Agency for Healthcare Research and Quality, Rockville, Maryland \\ ${ }^{3}$ Division of General Medicine and Clinical Epidemiology, Department of Medicine University of North Carolina School of Medicine, \\ Chapel Hill, North Carolina
}

Ann Fam Med 2018;16(Suppl_1)S2-S4. https://doi.org/10.1370/afm.2227.

$\mathrm{P}$ rimary care is foundational to the US health care system and key to improving health, reducing cost, and improving patient experience. ${ }^{1}$ Yet, primary care has been struggling with increasing demands and expectations, diminishing economic margins, and a challenging work environment. ${ }^{2,3} \mathrm{At}$ the same time, primary care clinicians are faced with an aging population and complex patients, ${ }^{4}$ often with insufficient time to address their patients' needs.

For the past 15 years, policy makers, health system leaders, researchers, physician organizations, and individual practices have been working to design, test, and implement innovative models of primary care and strategies to pay for it. Most of these efforts have focused on the development and spread of the patient-centered medical home model, but true and lasting transformation has been hard to achieve. In spite of these challenges, the US health care system needs primary care to succeed at effective and sustainable transformation that can deliver high-quality, comprehensive, teambased, coordinated, patient-centered care and utilize health information technology to manage population health and ongoing practice improvement. ${ }^{3}$ Payers are not only expecting but demanding this transformation. The Medicare Access and CHIP Reauthorization Act of 2015 (MACRA) established the Quality Payment

Conflicts of interest: Shoemaker serves as a medical advisory board member for Emmi Solutions for their medication adberence module.

\section{CORRESPONDING AUTHOR}

Sarah J. Shoemaker, PhD, PharmD

Abt Associates, Inc

10 Fawcett $\mathrm{St}$

Cambridge, MA 02138

sarah_shoemaker@abtassoc.com
Program, which consolidates previous Medicare quality measurement efforts in outpatient practices (the Physician Quality Reporting System, the Physician Value-Based Modifier Program, and Meaningful Use) to incentivize continuous improvement. MACRA also rewards advanced primary care practices with new alternative payment models that offer more flexibility beyond straight fee-for-service revenue generation and care delivery (eg, Comprehensive Primary Care Plus).

In 2015 the Agency for Healthcare Research and Quality (AHRQ) launched EvidenceNOW: Advancing Heart Health in Primary Care with an aim of ensuring primary care practices obtain and implement the latest evidence they need to improve the health of their patients. The goal is to understand how best to build and support the capacity of primary care practices to receive and incorporate new evidence and models of care. Aligning with Million Hearts, a national initiative with the aim of preventing 1 million heart attacks and strokes, ${ }^{5}$ EvidenceNOW focused on improving the delivery of the ABCS - aspirin use in high-risk individuals, blood pressure control, cholesterol management, and smoking cessation. AHRQ funded 7 regional cooperatives, each with a unique approach to providing and evaluating external quality improvement support on practices' capacity and ABCS performance, ${ }^{6-8}$ to support more than 1,500 small to medium-size primary care practices. AHRQ also funded an independent, national evaluation team to perform cross-cooperative analyses of ABCS delivery, practice capacity building, intervention implementation, and contextual factors. ${ }^{9}$ Together, EvidenceNOW aspires to advance cardiovascular health while elucidating pathways to increasing primary care capacity for evidence implementation, and to create a blueprint for future programs interested in pursuing primary care transformation. 
This supplement consists of 8 original research articles representing all 7 regional cooperatives and the national evaluation team. At the outset of the program, the cooperatives and national evaluation team harmonized a number of metrics, especially for ABCS and practice capacity. In addition, each cooperative as part of its own robust evaluation plan is collecting some unique metrics specific to its own study aims. The supplement also includes an overview and rationale from AHRQ and 2 commentaries from nationally recognized experts in the field of primary care research and practice transformation. Although the articles report early findings that represent a range of topics and empirical approaches, together they expand our understanding of the current performance and capacity of primary care for improving evidence-based care and how to provide external quality improvement support to primary care practices.

This supplement begins with the AHRQ's Chief Medical Officer, David Meyers and his colleagues ${ }^{10}$ describing their design decisions for the EvidenceNOW initiative, including the balance they aimed to achieve between their research goals and the realworld implementation of quality improvement strategies in small and medium-size practices.

The first 3 original research articles examine preintervention performance on ABCS measures and practice capacity for implementing new evidence. In the first 2 articles, the authors examine baseline performance on the measures. Shelley et a ${ }^{11}$ describe the baseline performance of small, urban primary care practices in New York City on all 4 ABCS measures, and Henderson et $\mathrm{al}^{12}$ focus on baseline performance on the blood pressure control measure of practices in North Carolina. Both studies examine the relationship between performance on the measure(s) and practice characteristics, as well as quality improvement leadership capability in the case of Henderson et al. Shelley et al also examine the association between measure performance and baseline practice capacity based on adaptive reserve ${ }^{13}$ and the Change Process Capability Questionnaire (CPCQ). ${ }^{14}$ Balasubramanian et al, ${ }_{1}^{15}$ the EvidenceNOW national evaluation team, report on the baseline practice capacity (based on the CPCQ) of 1,181 small and medium-size primary care practices from across the 12 participating EvidenceNOW states. They examine the association between practice characteristics and the CPCQ scores. Balasubramanian et al also examine the association of major disruptive events on practice capacity across practices within EvidenceNOW.

Similarly, the next 2 articles by Cuellar et a ${ }^{16}$ and Mold et $\mathrm{al}{ }^{17}$ examine what might explain the current state of practices' performance on the ABCS and prac- tice capacity-burnout and major disruptive events, respectively. Cuellar et al report on the differences by ownership type in self-reported work environment, culture of learning, psychological safety, and burnout of the participating practices in Virginia. Mold et al describe the rate of major disruptive events in a cohort of small to medium-size primary care practices in Oklahoma. Some disruptive events include practice relocation, changes in ownership or key staff, and implementation of a new electronic health record or other practice system.

The articles by English et $\mathrm{al}^{18}$ and McHugh et a ${ }^{19}$ describe implementation of different aspects of their interventions in their respective regional cooperatives. English et al describe their community engagement process, called Boot Camp Translation, to develop locally tailored cardiovascular disease patient engagement materials. McHugh et al describe enablers and barriers to implementation of the practice facilitatorsupported quality improvement program from the perspective of both practice leaders and practice facilitators.

The last original research article in this supplement is from Fagnan et $\mathrm{al}_{1}{ }^{20}$ who describe the approaches used to recruit practices for participation in EvidenceNOW and the associated costs based on the experience of 2 of the regional cooperatives in EvidenceNOW.

Finally, 2 invited commentaries are provided from experts in the field. ${ }^{21,22}$ We asked them to reflect on the preliminary findings from across EvidenceNOW grantees and the implications for primary care.

We hope that this supplement offers a lens into the current capacity of small and medium-size primary care practices for improving evidence-based care, as well as insight into the factors affecting performance and the approaches to external quality improvement support. We expect this supplement will pique readers' interest to watch for the forthcoming findings ${ }^{12,13}$ from the EvidenceNOW initiative, with the ultimate aim of determining "what works best in building practices' capacity for ongoing improvement."10 These findings will inform the path to success for primary care in new payment models and the success of a US health care system built on highly effective and sustainable primary care.

To read or post commentaries in response to this article, see it online at http://www.AnnFamMed.org/content/16/Suppl_1/S2.

Key words: primary health care; quality improvement; evidence-based practice; organizational innovation; patient-centered care

Submitted February 10, 2018; accepted February 20, 2018.

Funding support: Publication of this article was supported by the Agency for Healthcare Research and Quality (AHRQ) through contract No. HHSA2990201200019I. 
Disclaimer: This work represents the opinions of the authors and should not be interpreted as official positions of the Agency for Healthcare Research and Quality or the US Department of Health and Human Services.

\section{References}

1. Berwick DM, Nolan TW, Whittington J. The triple aim: care, health, and cost. Health Aff (Millwood). 2008;27(3):759-769.

2. Meyers DS, Clancy CM. Primary care: too important to fail. Ann Intern Med. 2009;150(4):272-273.

3. Bodenheimer T, Pham HH. Primary care: current problems and proposed solutions. Health Aff (Millwood). 2010;29(5):799-805.

4. Ward BW, Schiller JS, Goodman RA. Peer reviewed: Multiple chronic conditions among us adults: A 2012 update. Prev Chronic Dis. 2014;11:E62.

5. US Dept Health and Human Services. Million Hearts Web site. https://millionhearts.hhs.gov/index.html.

6. Parchman ML, Fagnan LJ, Dorr DA, et al. Study protocol for "Healthy Hearts Northwest": a $2 \times 2$ randomized factorial trial to build quality improvement capacity in primary care. Implement Sci. 2016;11(1):138.

7. Shelley DR, Ogedegbe G, Anane $S$, et al. Testing the use of practice facilitation in a cluster randomized stepped-wedge design trial to improve adherence to cardiovascular disease prevention guidelines: HealthyHearts NYC. Implement Sci. 2016;11(1):88.

8. Weiner BJ, Pignone MP, DuBard CA, et al. Advancing heart health in North Carolina primary care: the Heart Health NOW study protocol. Implement Sci. 2015;10(1):160.

9. Cohen DJ, Balasubramanian BA, Gordon L, et al. A national evaluation of a dissemination and implementation initiative to enhance primary care practice capacity and improve cardiovascular disease care: the ESCALATES study protocol. Implement Sci. 2016;11(1):86.

10. Meyers D, Miller T, Genevro J, et al. EvidenceNOW: balancing primary care implementation and implementation research. Ann Fam Med. 2018;16(Suppl 1):S5-S11.

11. Shelley D, Blechter B, Siman N, et al. Quality of cardiovascular disease care in small urban practices. Ann Fam Med. 2018;16(Suppl 1):S21-S28.
12. Henderson K, DeWalt DA, Halladay J, et al. Organizational leadership and adaptive reserve in blood pressure control: the Heart Health NOW Study. Ann Fam Med. 2018;16(Suppl 1):S29-S34.

13. Jaén CR, Crabtree BF, Palmer RF, et al. Methods for evaluating practice change toward a patient-centered medical home. Ann Fam Med. 2010;8(Suppl 1):S9-S20.

14. Solberg LI, Asche SE, Margolis KL, Whitebird RR. Measuring an organization's ability to manage change: the change process capability questionnaire and its use for improving depression care. Am J Med Qual. 2008;23(3):193-200.

15. Balasubramanian BA, Marino M, Cohen DJ, et al. Use of quality improvement strategies among small to medium-size US primary care practices. Ann Fam Med. 2018;16(Suppl 1):S35-S43.

16. Cuellar A, Krist AH, Nichols LM, Kuzel AJ. Effect of practice ownership on work environment, learning culture, psychological safety, and burnout. Ann Fam Med. 2018;16(Suppl 1):S44-S51.

17. Mold JW, Walsh M, Chou AF, Homco JB. The alarming rate of major disruptive events in primary care practices in Oklahoma. Ann Fam Med. 2018;16(Suppl 1):S52-S57.

18. English AF, Dickinson LM, Zittleman $L$, et al. A community engagement method to design patient engagement materials for cardiovascular health. Ann Fam Med. 2018;16(Suppl 1):S58-S64.

19. McHugh M, Brown Tiffany, Liss DT, Walunas TL, Persell SD. Practice facilitators' and leaders' perspectives on a facilitated quality improvement program. Ann Fam Med. 2018;16(Suppl 1):S65-S71.

20. Fagnan LJ, Walunas TL, Parchman ML, et al. Engaging primary care practices in studies of improvement: did you budget enough for practice recruitment? Ann Fam Med. 2018;16(Suppl 1):S72-S79.

21. Casalino LP. Technical assistance for primary care practice transformation: free help to perform unpaid labor? Ann Fam Med. 2018;16(Suppl 1):S12-S15.

22. Bitton A. Finding a parsimonious path for primary care practice transformation. Ann Fam Med. 2018;16(Suppl 1):S16-S19.

23. Ono SS, Crabtree BF, Hemler JR, et al. Taking innovation to scale in primary care practices: the functions of health care extension. Health Aff (Millwood). 2018;37(2):222-230.

24. Dorr DA, Cohen DJ, Adler-Milstein J. Data-driven diffusion of innovations: successes and challenges in 3 large-scale innovative delivery models. Health Aff (Millwood). 2018;37(2):257-265. 